\title{
AN INVESTIGATION OF ACADEMIC WRITING PROBLEMS LEVEL FACED BY UNDERGRADUATE STUDENTS AT AL IMAM AL MAHDI UNIVERSITY - SUDAN
}

\author{
Amin Ali Al Mubarak \\ Department of English, University of Al Imam Al Mahdi, Sudan \\ E-mail: amino.last25@gmail.com
}

\begin{abstract}
APA Citation: Al Mubarak, A. A. (2017). An investigation of academic writing problems level faced by undergraduate students at Al Imam Al Mahdi University - Sudan. English Review: Journal of English Education, 5(2), 175-188
\end{abstract}

\begin{abstract}
Academic writing skills mostly involve the linguistic competence development of the students which many English Second Language learners may identify it as a challenging task. The main objective of this study is to look into various challenges encountered by English Second language students in academic writing in ordinary graduation project in the context of universities. Specifically, this research focuses on identifying the problems faced by the Arts Colleges within the University of Al Imam Al Mahdi, Sudan. The researcher used the student's project graduation to investigate the problems encountered by the students when they used their academic writing skills. To state the obstacles recognized by the examined students in academic writing skills, the researcher employed a descriptive method. The findings of this research revealed the most problematic area faced by the students. Finally, the results of this research may help the scholars to reflect on teaching practices and urge the goverment to help teachers' attempts to enhance the academic writing skills of their students at the University of Al Imam Al Mahdi, Sudan.
\end{abstract}

Keywords: academic writing, students, problems.

\section{INTRODUCTION}

Nowadays, English plays an essential part in educational activities. Students are relied on to impart mostly in the universities where English is the means of teaching. Learners confront the task of grasping content area in subjects such as mathematics, social studies, science, and business which are taught in English. In such cases, instructing and learning of English can help the students to bargain effectively with their academic requirements and to function productively in their disciplines and learned contexts (Adams \& Keene, 2000). Writing appears to be one of the most important, yet challenging, academic skills for university students to learn. This is particularly the case of foreign or second language learners. Academic writing plays an indispensable part in learning a foreign language. Non- native English speakers ought to be acquainted with writing procedures, components, and elements like the convention, objectivity, and unpredictability to utilize the language precisely and accurately.

Ismail (2011) pointed out that English writing bears chances for students to think critically and gives the inspiration to learn certain parts of academic writing like utilizing powerful word expressions and a great vocabulary. Also, academic writing includes certain components like basic deduction and self-expression that understudies ought to get amid the courses they attend. There are different parts of academic writing which must be studied and grasped such as arranging paragraphs by utilizing robust style of word structures, paraphrasing, and appropriate conjunctions. 
Academic writing is commonly characterized as scientific writing which is portrayed as organized research practiced and utilized by researchers at higher education level. Dynamic and quality research have dependably been the keystone of higher education. Research is primarily integrated with academic writing as genrebased pedagogies acknowledge the writing procedure as a necessary arranged with social and cultural response to specific contexts and communities. By applying different linguistics and rhetorical options to achieve important tasks in diverse settings, novice writers may allow themselves to accomplish their writing tasks after careful examination of the complicated variable in composition texts (Johns, 2008).

Writing abilities are a critical part of communication for the students all through their academic life since it permits them to arrange their sentiments and thoughts obviously and additionally to pass on significance through well - developed content. Academic writing appears to be one of the most important, yet a problematic academic ability for university students to learn. This is predominantly evident with second language learners (Negari, 2011). Students confronted problems in various areas ranging from spelling words correctly to how to develop an argument in one's essay.

Considerable number of research has recommended that writing in a second language learning context is a difficult and demanding task. Alsamadani (2010) pointed out that the "difficulty and complexity of academic writing arise from the fact that writing includes discovering a thesis, developing support for it, organizing, revising, and finally editing it to ensure an effective, error-free piece of writing." Moreover, Musa (2010) stated that writing is considered as a difficult skill to learn because it includes several components, for instance, grasp on spellings and punctuation, a comprehensive command of grammar, grasp on spellings and punctuation, use of appropriate vocabulary, suitable style to meet the expected readers' expectations and organizational skills.

Yiu (2009) said that much research had offered valuable insights into the fact that this trend "...led to the exponential growth of research in second language writing over the last decade and a half." Chou (2011) expressed that however there has been an expanded enthusiasm for writing yet there has been a lack of research in this field in English as second language settings as a significant portion of research studies identified related to writing skills has been done in the English as second language contexts such as Australia, Canada, England, New Zealand, and America. He has additionally clarified that the announced research in this field can be separated into four classifications. The first group research studies explored the faculty standpoint concerning the academic writing for instance, Zhu (2004) and Casanave \& Hubbard (1992). The second type examined the students for instance, Grami (2010) and Yiu (2009). The third class investigated the students writing sample for example, Ezza (2010) and Tahaineh (2010), and the last group tried to examine the discernments of the students against the academic advisors for instance, Bacha and Bahous (2008) and Myles and Cheng (2003).

Moreover, it has also been stated that much of the research in the past two eras has mainly concentrated on either product, process or both" (Yiu, 2009). Various studies have been carried out to distinguish the issues of English as second language learners that faced in their writing. For instance, has expressed that Arab students' blunders in academic writing mostly fall in the classification of grammar and syntax. While, Noor (1996) who explored and analysed various of studies carried out on English as second language learners' syntactic mistakes and expressed that the students' blunders can be sorted in seven 
syntactic subcategories: verbs, prepositions, conjunctions, articles, relative clauses, sentence structure and adverbial clauses. Next, Mahmoud (2005) explored English as second language learners syntactic blunders also found out that verbs and prepositions are the most challenging areas in this regard.

Regarding the problems of academic writing, Khan (2011) who recently conducted a study to explore the problems of Saudi university students, has mentioned that they face numerous difficulties in phoneme clusters, spellings, grammar, mistakes due to first structure, doubling of subjects, language interference, doubling of preposition, articles, tenses, appropriate vocabulary, wrong use of prefixes, and suffixes. Khan (2011) reviewed a number of studies in this respect and concluded that Arab learners' difficulties are caused by the shortage in the English language curricula obtainable by some schools and universities, dreadful teaching methodology and the problems with appropriate language environments and the lack of personal motivation on the part of the students.

Al Murshidi (2014) pointed out that the low of the language proficiency might also obstruct academic writing. As determined by Al-Khairy (2013), the subject of his study affirmed that their main difficulties encompass the inappropriate choice of vocabulary, grammatical errors, incorrect punctuation, and spelling irregular verbs. Other causes that could lead to the problem in academic writing are first language interference, insufficiency of views, and unclear guidance of the task. Saddler, Moran, Graham, \& Harris (2004) said that academic writing skill ought to start at elementary and secondary education so that when the learners are at univesity level, they should not battle with academic writing. Besides, they recommend a few rules in avoiding writing problems, namely: to provide exemplary writing instruction to all the students from the start, beginning in university level, and to offer early supplementary writing instruction aimed at avoiding or at least alleviating later writing difficulties.

Further, Lea and Street (1998)

utilized an ethnographic qualitative approach which incorporated semistructured interviews with the teachers and the learners, respondents observations, models of student's writing, and written feedback on students. They found that the learners experienced problems with writing, mainly with conflicting, distinct and implicit requirements for writing in various courses. In addition, Gambell (1991) finds that the students discernments toward their own writing and how they go about academic writing found that even fruitful learners are awkward with their own university-level writing and that writing is challenging and distressing to a hefty portion of them.

Furthermore, Lee and Tajino (2008) pointed out that a number of researchers explored English as second langauge student discernments and they all approve that it is significant to include the students' recommendations in developing academic writing programmes. Some found that the students consider that interaction with native speakers will resolve their writing problems

Finally, the previous studies endeavored to give answers to the challenge of students in academic writing in English as second language contexts. As a result, research input various previous studies in academic writing. The research continues to explore ways in which English as second language students can be developed academic writing. However, academic writing will continue to posing a challenge to these students due to several factors. Accordingly, this study is based on the following questions:

1. What are the academic writing problems encountered by English second language earners? 2. What are the factors that may cause difficulties academic writing problems? 


\section{METHOD}

The present study intends to investigate the issues of writing problems faced by postgraduate students at Al Imam Al Mahdi University in Sudan. Besides, this paper reacts to the inadequacy of research in this particular area at the university level. Currently, there is limited research that addresses the issues under scrutiny. It is aimed that the outcomes of this study could assist the administrative authorities to enhance the level of translation skill at the university level. The data for the present study were collected from 15 graduation project for the year 2017. The collect data was used in identifying the issues of academic writing for English as second language at $\mathrm{Al}$ Imam $\mathrm{Al}$ Mahdi University in Sudan. A quantitative method was used in collecting the data: 15 B.A. graduation project checked in order to identify the issues of academic writing for English as a Second language in Sudan. The number of the graduation project involved in this study was 15 , and their identity was kept confidential. Apart from that, the researcher believes that the respondent's project demography and gender, have no impact on the analysis of this study.

\section{RESULTS AND DISCUSSION}

The analysis was carried out in order to find out about the potential isuues of academic writing in English as a second language for the learners in Sudan. The result of gradution project that analysised were listed below

\section{Issues of the first student graduation project}

Figure 1 shows the frequency of issues in the first grdaution project. Seven percent of the of the first student project found having problems with the use of articles and fortytwo percent of the same project show weakness in the use of punctuation. Only nine percent of the first student projectdisplayed difficulties in employing theprepositions. Similarly, four percent of the first student project found have problem with use of irregular verbs and eighteen percent of same project found have problems used poor expressions. Moreover, only twopercent of first student project faced problems in consistency and twenty-four percent of same project found have problems with used of paralleled structure. Finally, tweleve percent of first student project found have problems with used of verb tense.

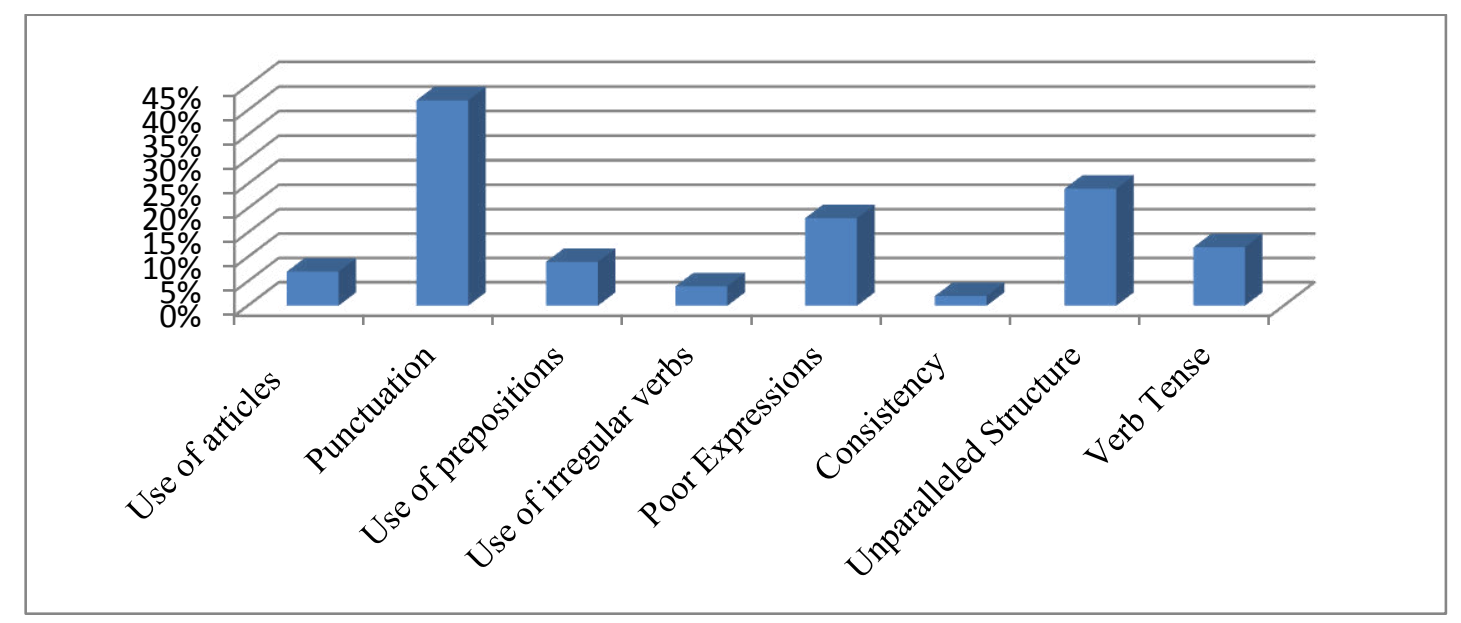

Figure 1

\section{Issues of the second student graduation project}

Figure 2 shows the frequency of issues in the second grdaution project. Seven percent of the of the second students projectshows problems with the use of articles and twenty- eight percent of the same project do have weakness in the utilization of 
punctuation. Only tweleve percent of the second student project have difficulties in employing the prepositions. Similarly, fifteen percent of the second students project found have problem with usage of irregular verbs and eighteen percent of the same project found have problems used poor expressions. Additionally, only seven percent of the second student project have problems in consistency and nine percent of the same project found have problems with used of paralleled structure. Finally, four percent of the second student project found have problems with used of verb tense.

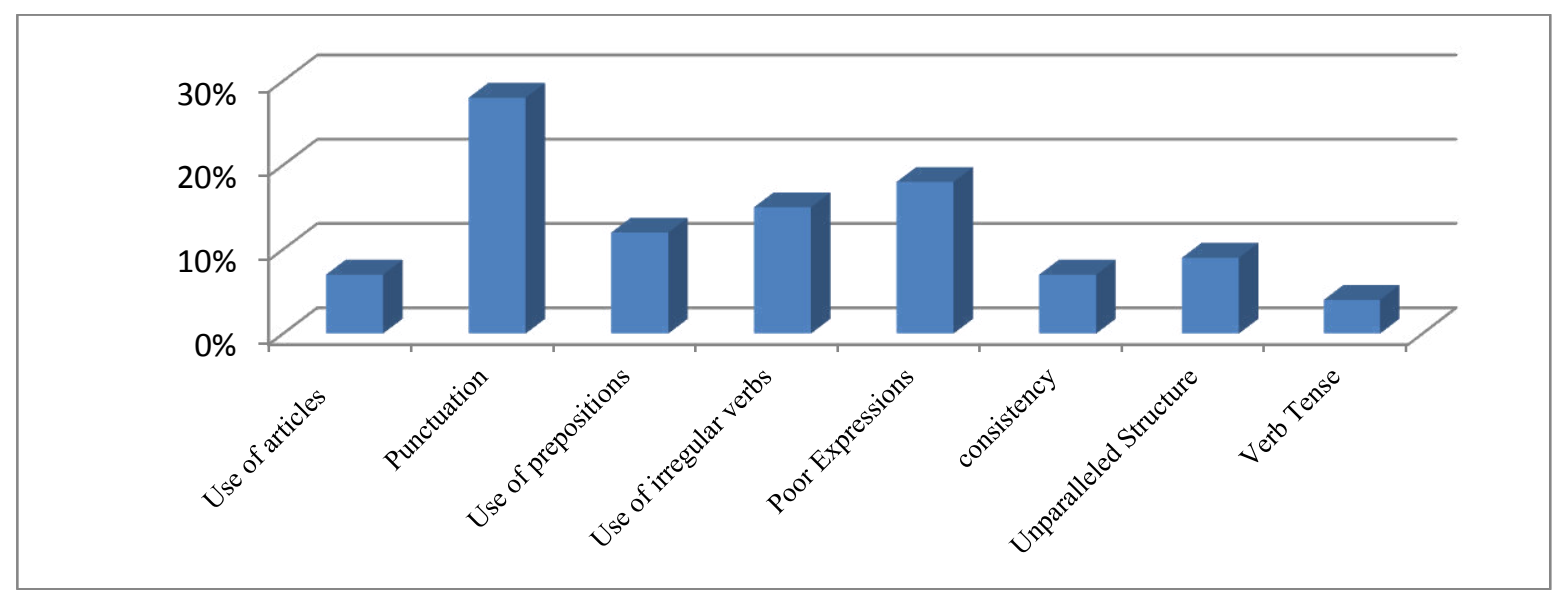

Figure 2

\section{Issues of the third student graduation project}

Figure 3 shows the frequency of issues in the third grdaution project. Two percent of the of the third students project have difficulties with the use of articles and twenty- two percent of the same project do have weakness in the utilization of punctuation. Only twenty-five percent of the third student projection have problems in using the prepositions. Similarly, seven percent of the same project found have difficult with usage of irregular verbs and tweleve percent of the third student project show poor expressions. Additionally, only four percent of the same project faced problems in consistency and ten percent of the third student project found having problems with used of paralleled structure. Finally, eighteen percent of the same project found having problems with used of verb tense.

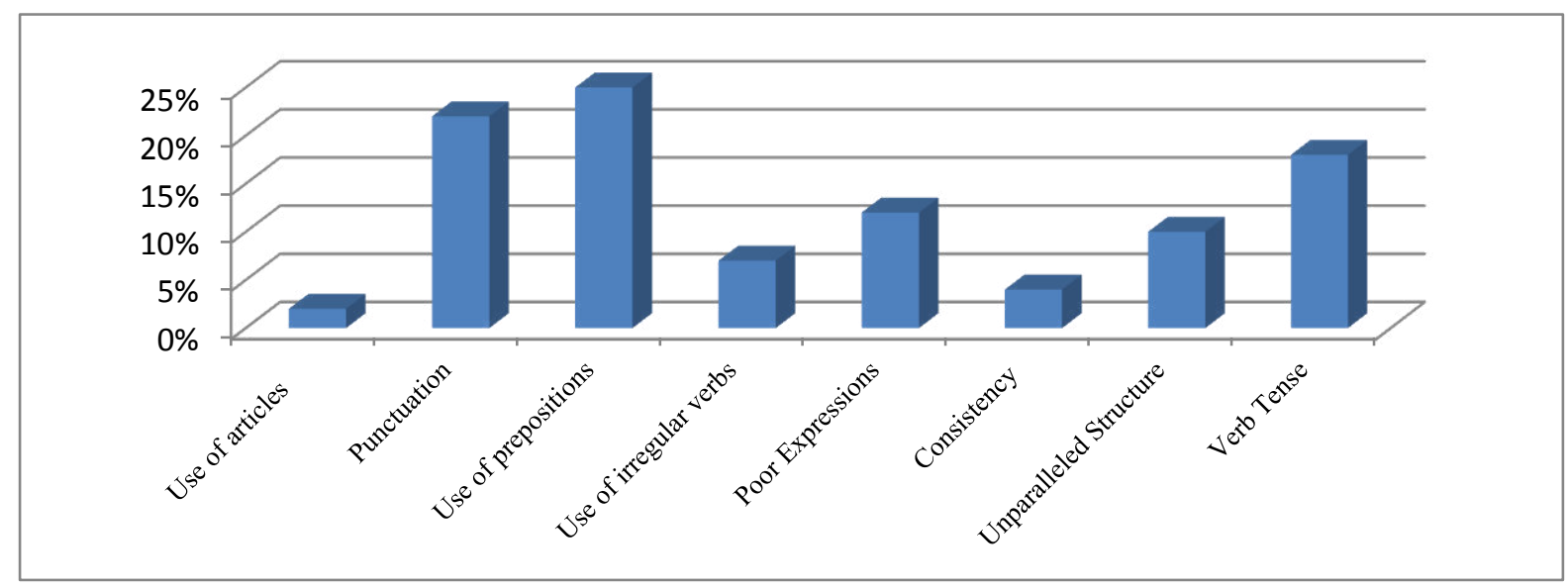

Figure 3 


\section{Issues of the fourth student graduation project}

Figure 4 shows the frequency of issues in the fourth grdaution project. Eight percent of the of the fourth students project have difficulties with the use of articles and twenty percent of the same project do have weakness in the utilization of punctuation. Only thrity-two percent of the fourth student project have problems in using the prepositions. Similarly, twleve percent of the same project found have difficult with usage of irregular verbs and twenty-five percent of the fourth student project show poor expressions. Additionally, only four percent of the same project faced problems in consistency and six percent of the fourth student project found having problems with used of paralleled structure. Finally, three percent of the same project found having problems with used of verb tense

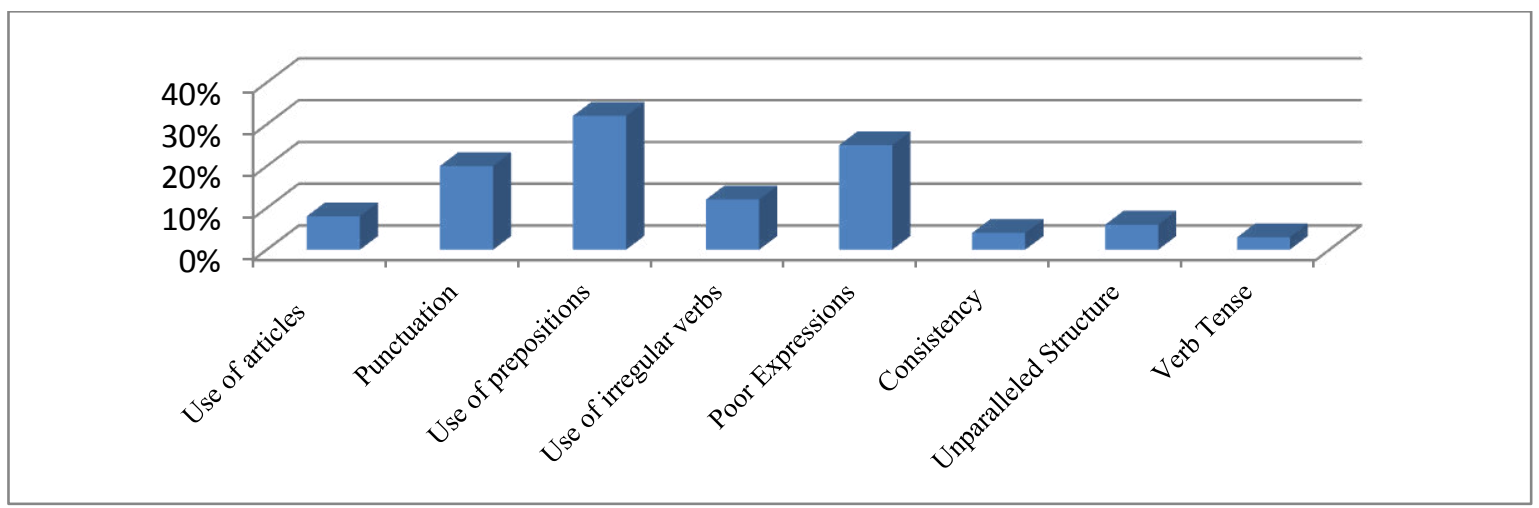

Figure 4

\section{Issues of the fifth student graduation project}

Figure 5 shows the frequency of issues in the fifth grdaution project. Ninteen percent of the of the fifth students project reveals the difficulties with the use of articles and twenty-eight percent of the same project show the weakness in the utilization of punctuation. Only eighteen percent of the fifth student project reveals problems in using the prepositions. Similarly, only two percent of the same project found have difficult with usage of irregular verbs and thirteen percent of the fifth student project show poor expressions. Additionally, eighteen percent of the same project reveals the problems in consistency and one percent of the fifth student project found having problems with used of paralleled structure. Finally, only one percent of the same project show problems with used of verb tense

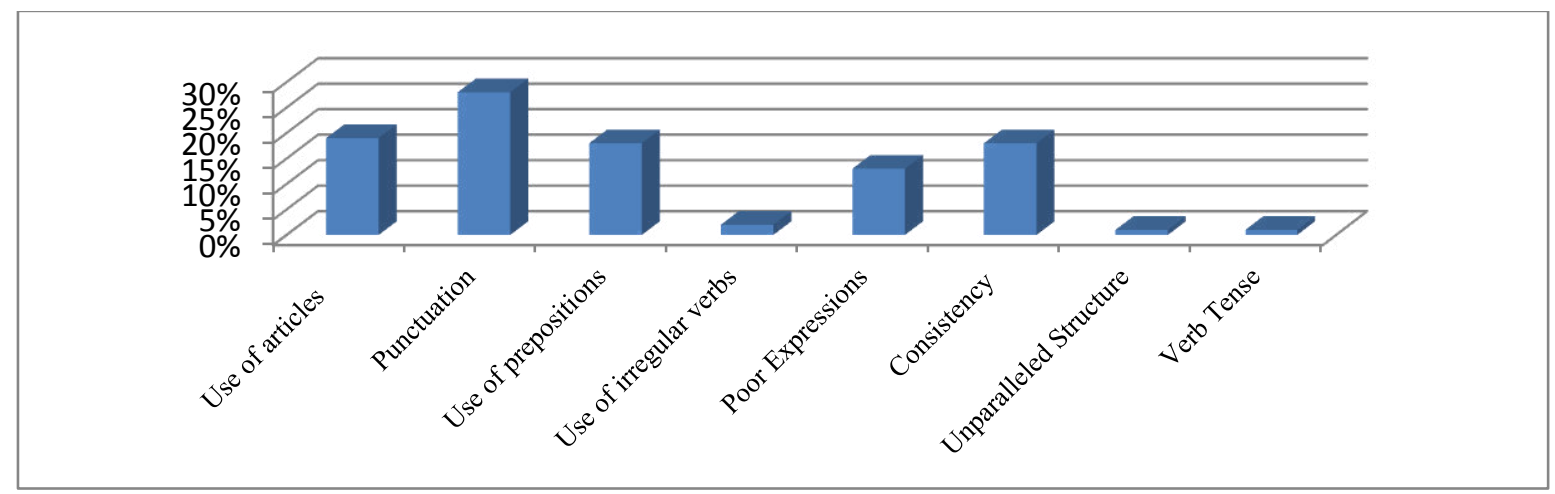

Figure 5 


\section{Issues of the sixth student graduation project}

Figure 6 shows the frequency of issues in the sixth grdaution project. Four percent of the of the sixth students project depicted the difficulties with the use of articles and fortyfive percent of the same project show the weakness in the utilization of punctuation. Only thirty percent of the sixth student project reveals problems in using the prepositions. Similarly, only five percent of the same project found have difficult with usage of irregular verbs and ten percent of the sixth student project show poor expressions. Additionally, four percent of the same project reveals the problems in consistency and one percent of the sixth student project found having problems with used of paralleled structure. Finally, only one percent of the same project show problems with used of verb tense.

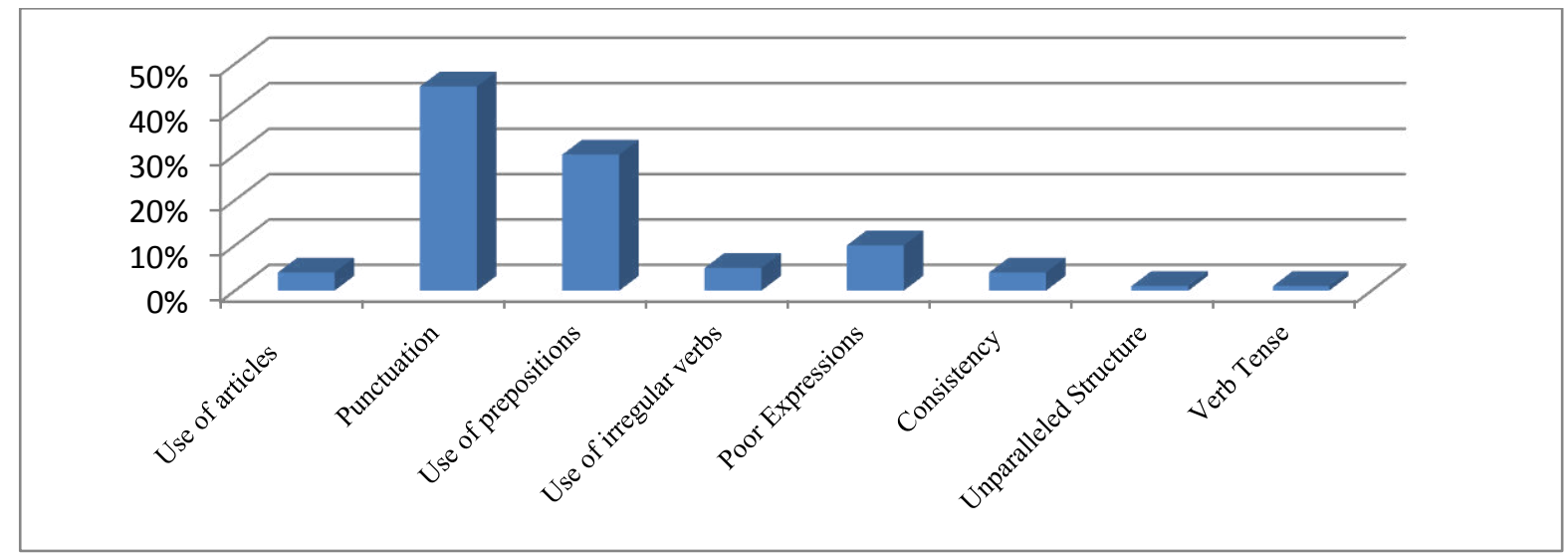

Figure 6

\section{Issues of the seventh student graduation project}

Figure 7 shows the frequency of issues in the seventh grdaution project. one percent of the of the seventh students project represented the difficulties with the use of articles and fifty-three percent of the same project display the weakness in the utilization of punctuation. Only twenty-two percent of the seventh student project discloses problems in using the prepositions.
Similarly, only one percent of the same project found have difficult with usage of irregular verbs and eight percent of the seventh student project indicates poor expressions. Additionally, tweleve percent of the same project reveals the problems in consistency and one percent of the seventh student project found having problems with used of paralleled structure. Finally, only two percent of the same project show problems with used of verb tense.

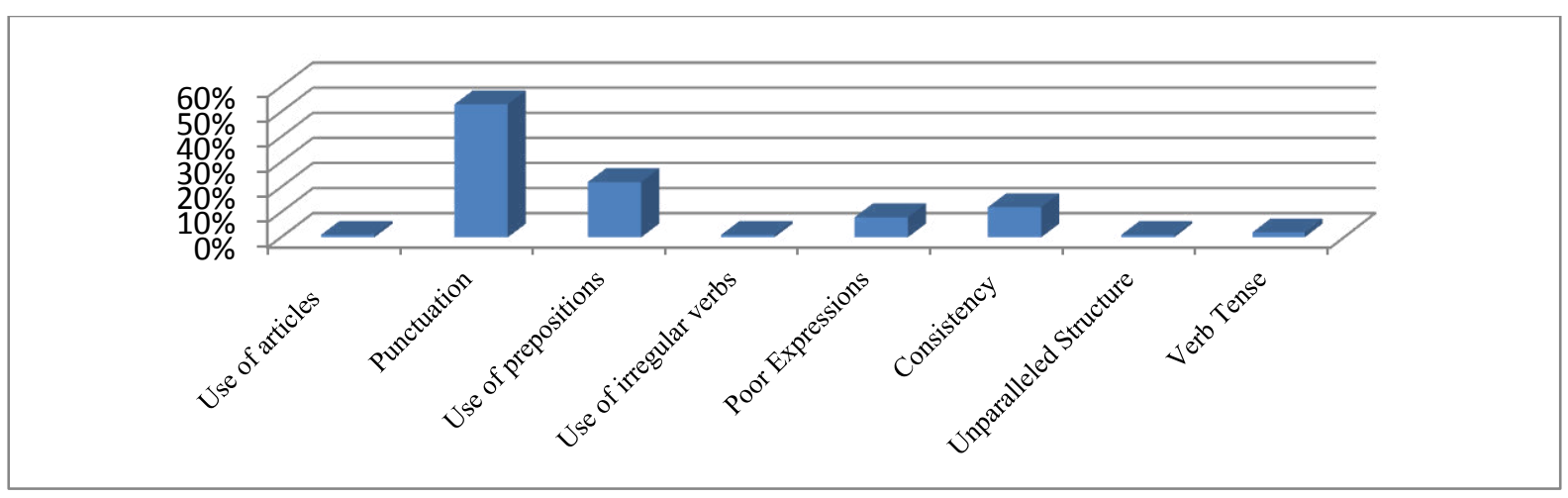

Figure 7 


\section{Issues of the eighth student graduation project}

Figure 8 shows the frequency of issues in the eighth grdaution project. one percent of the of the eighth students project signified the problems with the use of articles and tweleve percent of the same project show the debility in the utilization of punctuation. Only eighteen percent of the eighth student project reveals problems in using the prepositions. Similarly, only one percent of the same project found have difficult with usage of irregular verbs and seven percent of the eighth student project specifies poor expressions. Additionally, tweleve percent of the same project reveals the problems in consistency and one percent of the eighth student project found having problems with used of paralleled structure. Finally, fortyeight percent of the same project display problems with used of verb tense.

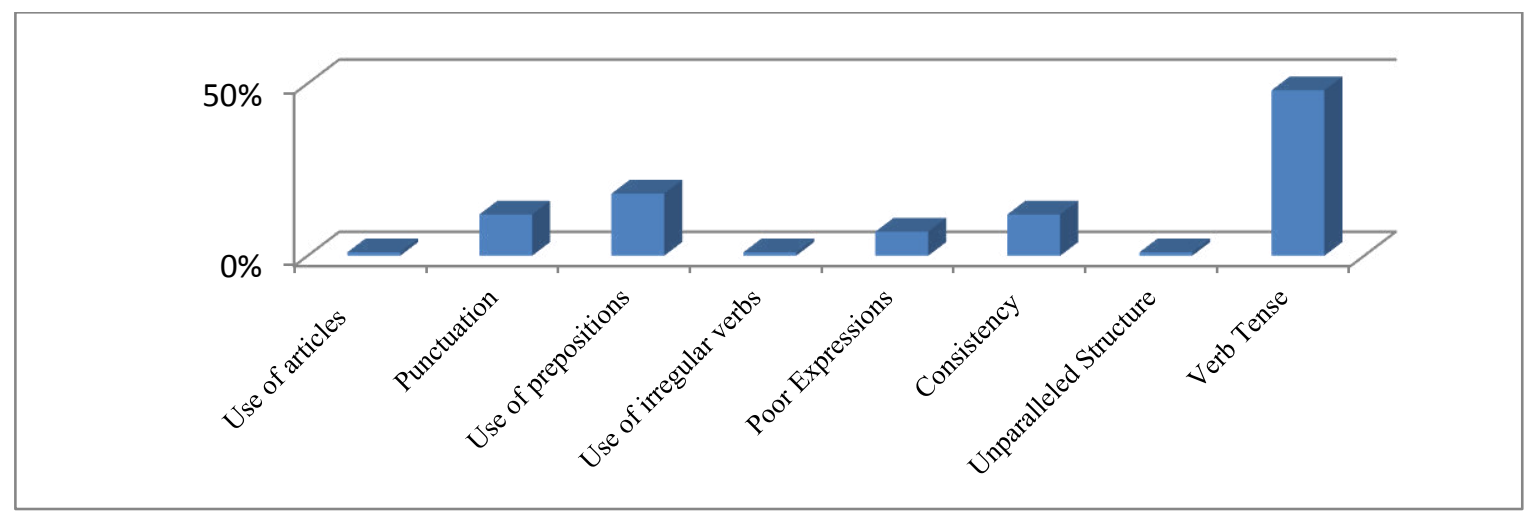

Figure 8

\section{Issues of the ninth student graduation project}

Figure 9 shows the frequency of issues in the ninth grdaution project. Three percent of the of the ninth students project showed difficulties with the use of articles and twenty-seven percent of the same project display the feebleness in the utilization of punctuation. Twenty- five percent of the ninth student project show problems in using the prepositions. Similarly, only four percent of the same project found have difficult with usage of irregular verbs and nine percent of the ninth student project specifies poor expressions. Additionally, tweleve percent of the same project reveals the problems in consistency and three percent of the ninth student project found having problems with used of paralleled structure. Finally, seventeen percent of the same project display problems with used of verb tense.

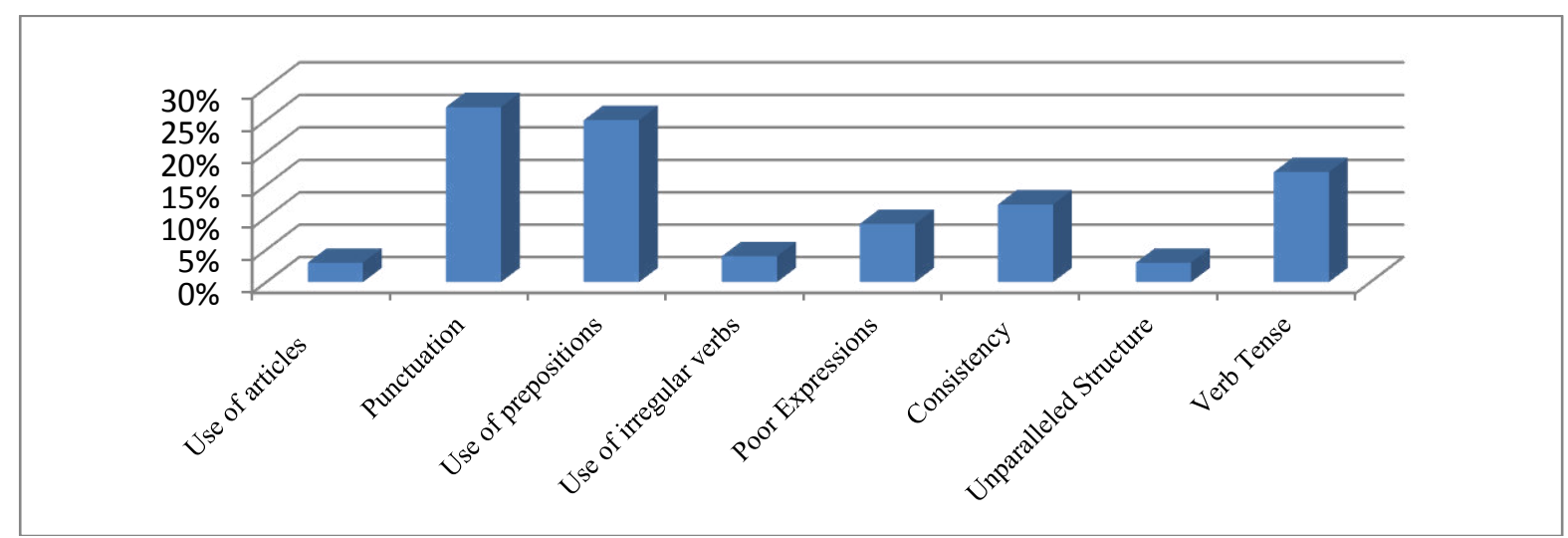

Figure 9 
Issues of the tenth student graduation project Figure 10 shows the frequency of issues in the tenth grdaution project. Three percent of the of the tenth students project showed problems with the use of articles and nine percent of the same project display the feebleness in the utilization of punctuation. Threeteen percents of the tenth student project show problems in using the prepositions. Similarly, only four percent of the same project found have difficult with usage of irregular verbs and nine percent of the tenth student project specifies poor expressions. Additionally, tweleve percent of the same project reveals the problems in consistency and five percent of the tenth student project found having problems with used of paralleled structure. Finally, forty percent of the same project display problems with used of verb tense.

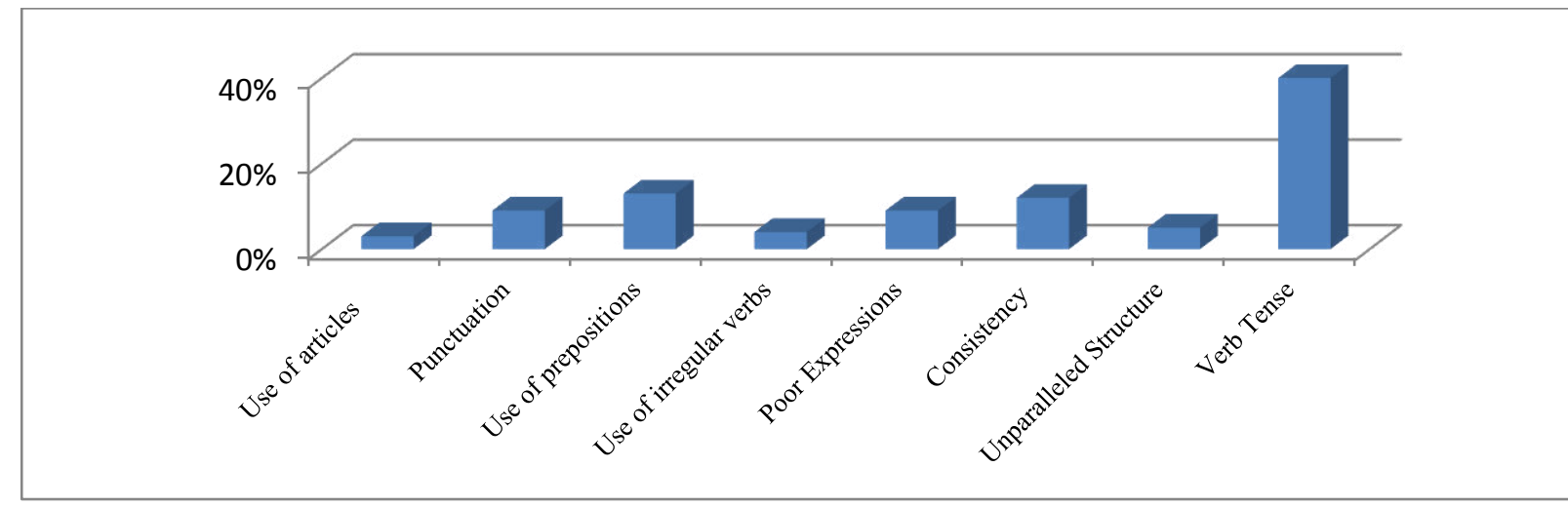

\section{Figure 10}

\section{Issues of the eleventh student graduation project}

Figure 11 shows the frequency of issues in the eleventh grdaution project. Six percent of the of the eleventh students project showed problems with the use of articles and nine percent of the same project display the feebleness in the utilization of punctuation. Ten percents of the eleventh student project show problems in using the prepositions. Similarly, only four percent of the same project found have difficult with usage of irregular verbs and thrity-four percent of the eleventh student project specifies poor expressions. Additionally, sixteen percent of the same project reveals the problems in consistency and five percent of the eleventh student project found having problems with used of paralleled structure. Finally, tweleve percent of the same project display problems with used of verb tense.

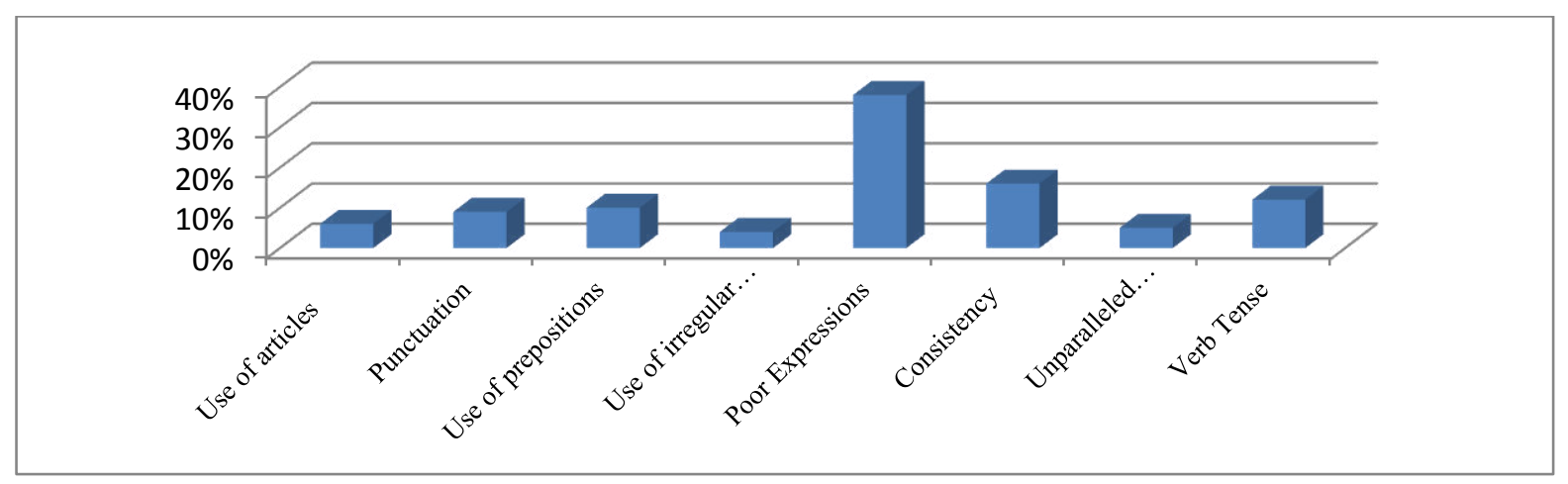

Figure 11 


\section{Issues of the twelfth student graduation project}

Figure 12 shows the frequency of issues in the tweleveth grdaution project. Six percent of the of the tweleveth students project showed problems with the use of articles and thrity-seven percent of the same project display the feebleness in the utilization of punctuation. Seventeen percents of the tweleveth student project show problems in using the prepositions. Similarly, only six percent of the same project found have difficult with usage of irregular verbs and fourteen percent of the tweleveth student project specifies poor expressions.

Additionally, thriteen percent of the same project reveals the problems in consistency and only two percent of the tweleveth student project found having problems with used of paralleled structure. Finally, five percent of the same project display problems with used of verb tense.

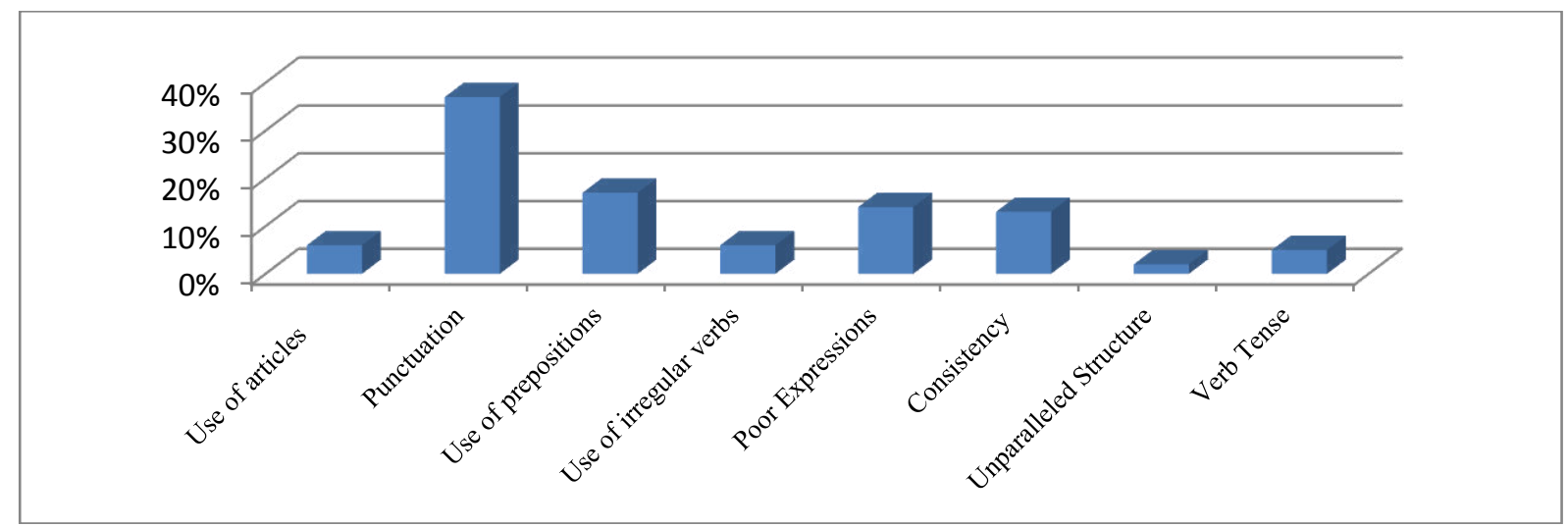

Figure 12

\section{Issues of the thirteenth student graduation project}

Figure 13 shows the frequency of issues in the thirteenth grdaution project. Two percent of the of the thirteenth students project showed problems with the use of articles and seven percent of the same project display the feebleness in the utilization of punctuation. Forty percents of the thirteenth student project show problems in using theprepositions. Similarly, only three percent of the same project found have difficult with usage of irregular verbs and eighteen percent of the thirteenth student project specifies poor expressions.

Additionally, ten percent of the same project reveals the problems in consistency and only nine percent of the thirteenth student project found having problems with used of paralleled structure. Finally, eleven percent of the same project display problems with used of verb tense.

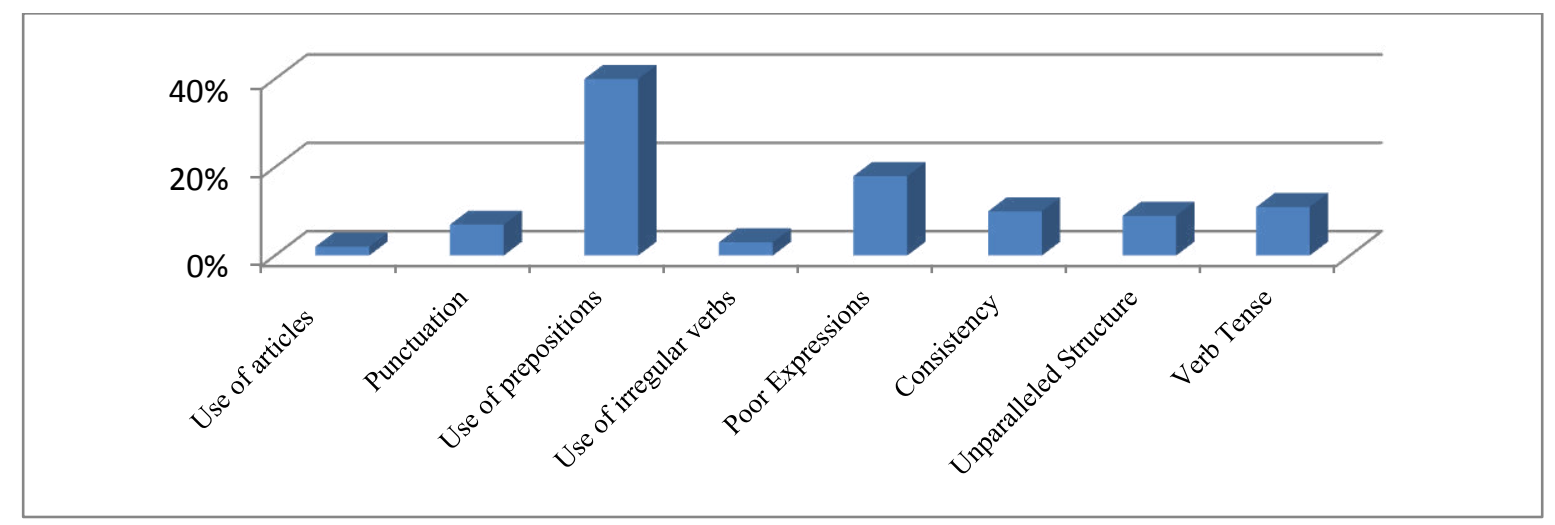

Figure 13 


\section{Issues of the fourteen student graduation project}

Figure 14 shows the frequency of issues in the fourteen grdaution project. Four percent of the of the fourteen students project showed problems with the use of articles and tweleve percent of the same project display the feebleness in the utilization of punctuation. Ten percents of the fourteen student project show problems in using the prepositions. Similarly, only two percent of the same project found have difficult with usage of irregular verbs and twelev percent of the fourteen student project specifies poor expressions. Additionally, fifty-two of the same project reveals the problems in consistency and only three percent of the fourteen student project found having problems with used of paralleled structure. Finally, five percent of the same project display problems with used of verb tense.

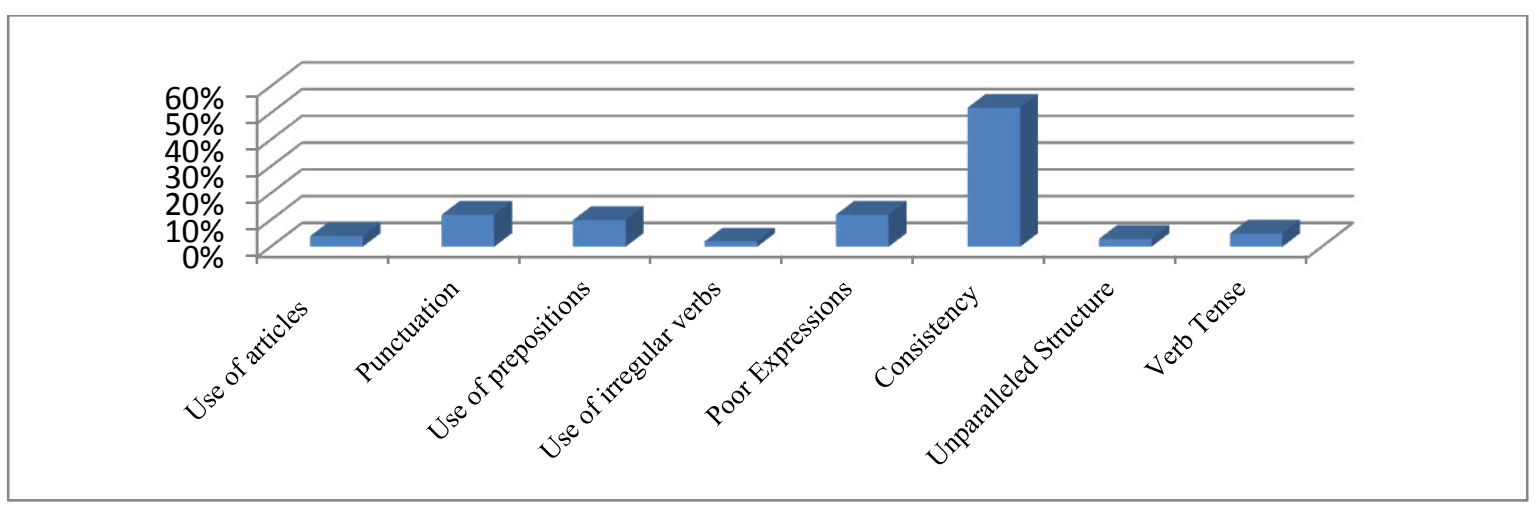

Figure 14

\section{Issues of the fifteenth student graduation} project

Figure 15 shows the frequency of issues in the fifteenth grdaution project. Three percent of the of the fifteenth students project showed problems with the use of articles and tweleve percent of the same project display the feebleness in the utilization of punctuation. Ten percents of the fifteenth student project show problems in using the prepositions. Similarly, only two percent of the same project found have difficult with usage of irregular verbs and sixteen percent of the fifteenth student project specifies poor expressions.

Additionally, threeteen of the same project reveals the problems in consistency and twenty-eight percent of the fifteenth student project found having problems with used of paralleled structure. Finally, eighteen percent of the same project display problems with used of verb tense.

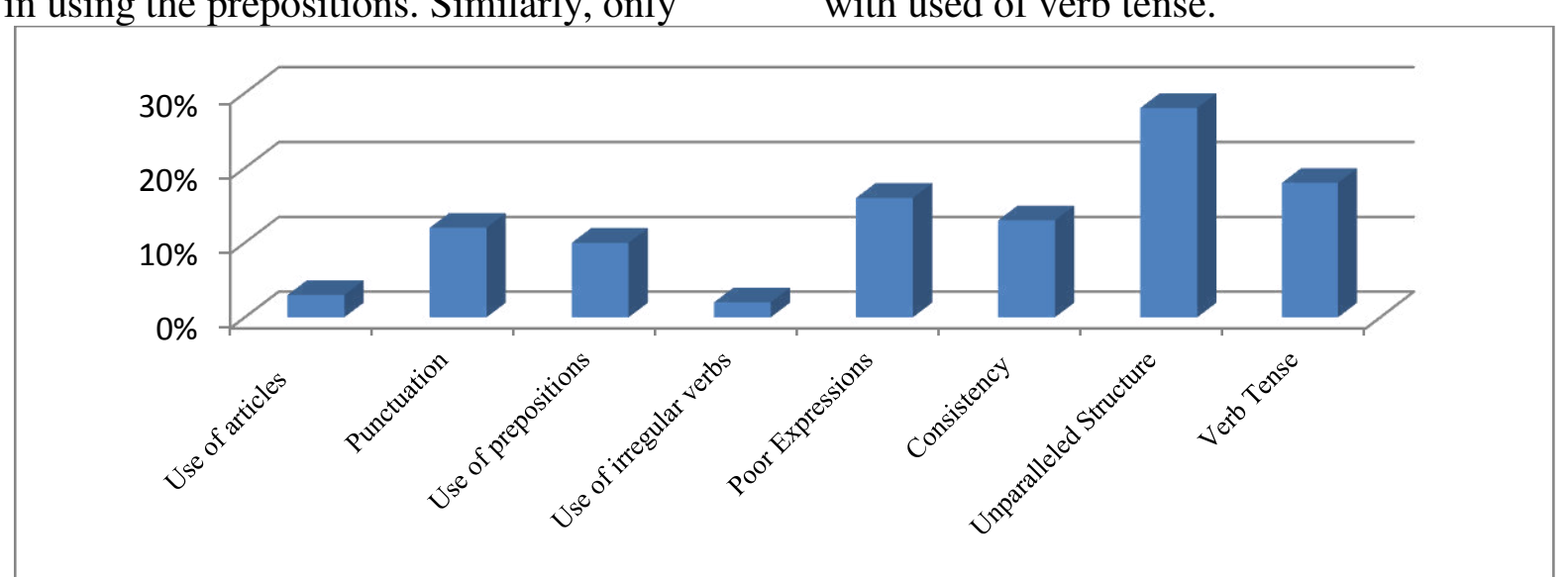

Figure 15 


\section{Over all fifteen student graduation project assessment for academic writing}

Figure 16 shows the frequency issues of fifteen student graduation project assessment for academic writing. Thirteen percent of the fifteen students graduation project showed problems with the use of articles and forty-five percent of the same project display the feebleness in the utilization of punctuation. Thirty-six percents of the fifteen students project show problems in using the prepositions.
Similarly, only nine percent of the same project found that the students have difficult with usage of irregular verbs and twentyseven percent of fifteen students graduation project specifies poor expressions.

Additionally, twenty-three of the same project reveals the problems in consistency and thirteen percent of the fifteen students graduation project found having problems with used of paralleled structure. Finally, fourteen percent of the same project display problems in using of verb tense.

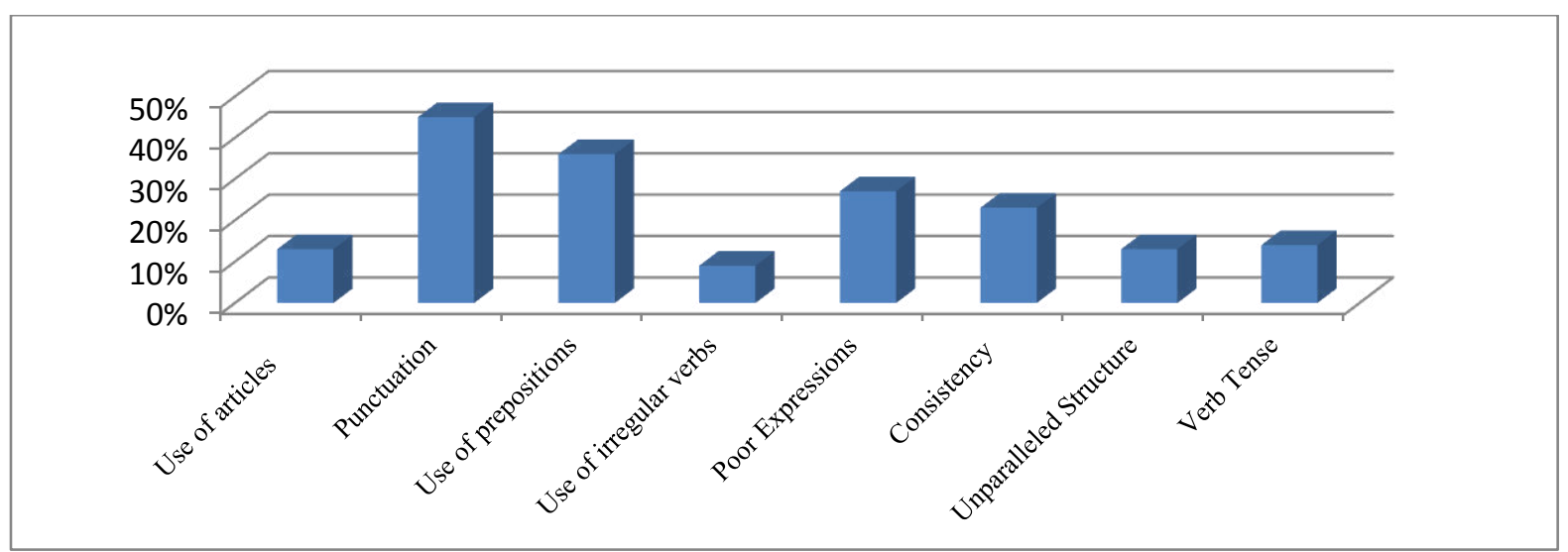

Figure 16

The primary intention of this study was to investigate the challenges of academic writing which a group of English as the second language learners undergraduate project had to encounter. One interesting finding which came to light through the present study is the significant role played by academic writing towards the students' overall English language learning experiences. Therefore, a broad investigation has been carried out on the difficulties of academic writing that faced undergraduate learners. The outcomes of this research revealed that students encountered various obstacles used academic writing. It is indisputable evidence that the knowledge of the grammar is necessary, and as it is said that leaning academic writing as the flesh of the language and grammar is the skeleton. An analysis of the students' graduation project revealed that various kinds of mistakes made by the students writing weak.
By examining the academic writing samples of the students, it can be presumed that a significant number of the students face academic writing problems. While writing, they show more concern for language related problems. The findings of the study revealed some issues that the students encountered in academic writing, for instance, the use of articles, punctuation, the use of prepositions, the use of irregular verbs, weak expressions, singular and plural, unparalleled structure, consistency and verb tense. Moreover, the study findings indicating that using relevant articles is the one of the problems that they face in their academic writing at the university level. This finding is also in line with the (AlKhasawneh \& Maher, 2010) who informed that the students are unable to use articles appropriately in their writings due to their limited grammar. Furthermore, the findings of the current study revealed that the 
students face difficulties in using punctuation which is extremely significant in academic writing.

This finding inline with Hutchinson \& Waters (1987) who also strongly suggested that it is important to to acquaint the learners with use of punctuation for smooth progression in academic writing. The 'use of irregular verbs' is another difficult area for the undergraduates which represented the use of past and past participle forms of irregular verbs. The findings also, revealed the problems in using appropriate prepositions and stand as problematic areas in academic writing tasks for the students which had been confirming in of numerous studies which reported that use of inappropriate prepositions is a major kind of error found in the academic writings of the Arab students (Al-Khairy, 2013). The students may need to enhance their consistency and connect words to their personal experience they may have to be motivated to write words frequently and consistently and attempt to paraphrase the meanings. The findings also indicate that the most common beliefs in the difficulty among students in academic writing are about paralleled structure. The findings from the present study are consistent with some previous findings which claimed that the ESL learners are inclined poor expressions than novice learners which is also the case in the present context. As has been reported in related studies, this is more so if the students are not familiar or lack experience, which in turn may fail to make metacognitive connection with. The study also revealed that the attitude of students towards academic writing with unique characteristics can be considered as a crucial factor in making academic writing more helpful for all students. Findings show that intervening strategies in using academic writing reveals the linguistics problems.

\section{CONCLUSION}

The present study shows that the students faced numerous challenges relating to academic writing at university level.

Successful academic writing is considered of utmost importance to the academic accomplishment of the English as second language students, especially in content areas in the contexts of tertiary levels. The present study investigated the challenging aspects of academic writing encountered by the students at the Al-Imam Al Mahdi University in Sudan. The significant results from this research revealed that students sampled were not familiar with the academic writing strategies. It is noteworthy that academic writing is reportedly considered as the most common activity at the university level. Unfortunately, related studies have discovered that the students are not always aware of the potential benefits of both the conscious and continuous use of academic writing which may help expedite and make the writing process more efficient. In answering the first research question of the study, i.e., What the academic writing problems encountered by English second language learners are, it was discovered that many challenges about academic writing experienced by the students while writing, they were articles, punctuation, prepositions, irregular verbs, poor expressions, consistency paralleled structure, and used of verb tense. In answering the second research question of the study, i.e., what the factors that may cause difficulties academic writing problems are, a considerable number of the project that was examined reported that they faced problems regardless of their language level proficiency when using morphology and syntactic properties to understand the meanings of words.

\section{REFERENCES}

Adams, K. H., \& Keene, M. (2000). Research and writing across the disciplines. New York: McGraw Hill.

Al-Khairy, M. A. (2013). Saudi English-major undergraduates' academic writing problems: A Taif university perspective. English Language Teaching, 6(6).

Al-Khairy, M. H. (2013). English as a foreign language learning demotivational factors as 
perceived by Saudi undergraduates. European Scientific Journal, 9(32).

Al-Khasawneh, F., \& Maher, S. (2010). Writing for academic purposes: Problems faced by Arab postgraduate students of the college of business, UUM. ESP World, 9(2), 1-23.

Al Murshidi, G. (2014). UAE university male students' interests impact on reading and writing performance and improvement. English Language Teaching, 7(9), 57.

Alsamadani, H. A. (2010). The relationship between Saudi EFL students' writing competence, L1 writing proficiency, and self-regulation. European Journal of Social Sciences, 16(1), 53-63.

Bacha, N. N., \& Bahous, R. (2008). Contrasting views of business students' writing needs in an EFL environment. English for Specific Purposes, 27(1), 74-93.

Casanave, C. P, \& Hubbard, P. (1992). The writing assignments and writing problems of doctoral students: Faculty perceptions, pedagogical issues, and needed research. English for Specific Purposes, 11(1), 33-49.

Chou, L. (2011). An investigation of Taiwanese Doctoral students' academic writing at a US university. Higher Education Studies, 1(2), 47-60.

Ezza, E. (2010). Arab EFL learners' writing dilemma at tertiary level. English Language Teaching, 3(4), 33.

Gambell, T. J. (1991). University education students' self-perceptions of writing. Canadian Journal of Education/Revue canadienne de l'éducation, 420-433.

Grami, M. A. (2010). The effects of integrating peer feedback into university-level ESL writing curriculum: A comparative study in a Saudi context (Unpublished Doctoral Dissertation).

Hutchinson, T., \& Waters, A. (1987). English for specific purposes. Cambridge: Cambridge University Press.

Ismail, S. A. A. (2011). Exploring students' perceptions of ESL writing. English Language Teaching, 4(2), 73.

Johns, A. M. (2008). Genre awareness for the novice academic student: An ongoing quest. Language Teaching, 41(2), 237.

Khan, I. A. (2011). Learning difficulties in English: Diagnosis and pedagogy in Saudi Arabia. Educational Research, 2(7), 1248-1257.

Lea, M. R., \& Street, B. V. (1998). Student writing in higher education: An academic literacies approach. Studies in Higher Education, 23(2), 157-172.

Lee, S. N., \& Tajino, A. (2008). Understanding students' perceptions of difficulty with academic writing for teacher development: A case study of the university of Tokyo writing program.

Mahmoud, A. (2005). Collocation errors made by Arab learners of English. Asian EFL Journal, 5, 1-9.

Musa, F. (2010). Teaching writing to post-secondary students: Procedure and technicalities in an EFL classroom. Paper presented at the First National Conference on English Language Teaching, Al-Quds Open University, Palestine. Retrieved from http://www.qou.edu/english/ conferences/firstNationalConference/pdfFiles/ farouqMusa. pdf.

Myles, J., \& Cheng, L.. (2003). The social and cultural life of non-native English speaking international graduate students at a Canadian university. Journal of English for Academic Purposes, 2(3), 247-263.

Negari, G. M. (2011). A study on strategy instruction and EFL learners' writing skill. International Journal of English Linguistics, 1(2), 299.

Noor, H. H. (1996). English syntactic errors by Arabic speaking learners: Reviewed. Retrieved from: files.eric.ed.gov/fulltext/ED423660.pdf

Saddler, B., Moran, S., Graham, S., \& Harris, K. R. (2004). Preventing writing difficulties: The effects of planning strategy instruction on the writing performance of struggling writers. Exceptionality, 12(1), 3-17.

Tahaineh, Y. S. (2010). Arab EFL university students' errors in the use of prepositions. Modern Journal of Applied Linguistics, 1(6), 76-112.

Yiu, R. H. H. (2009). Disciplinary writing: A case study of Hong Kong undergraduates undertaking their writing tasks. University of Leicester.

Zhu, W. (2004). Writing in business courses: An analysis of assignment types, their characteristics, and required skills. English for Specific purposes, 23(2), 111-135. 